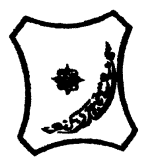

Bayero Journal of Pure and Applied Sciences, 12(1): 395 - 400

ISSN $2006-6996$

\title{
ADHERENCE TO ANTIHYPERTENSIVE MEDICATIONS IN PATIENTS ATTENDING PUBLIC HOSPITALS IN KANO STATE, NIGERIA
}

\author{
${ }^{1,2 *}$ Umar Idris Ibrahim, Shafiu Mohammed ${ }^{2}$, Abdulkadir Umar Zezi ${ }^{3}$ and ${ }^{4}$ Basira \\ Kankia Lawal \\ 1. Department of Clinical Pharmacy and Pharmacy Practice, Faculty of Pharmaceutical Sciences, \\ Bayero University Kano, Nigeria.
}

2. Department of Clinical Pharmacy and Pharmacy Practice, Faculty of Pharmaceutical Sciences, Ahmadu Bello University Zaria, Nigeria.

3. Department of Pharmacology and Therapeutics, Faculty of Pharmaceutical Sciences, Ahmadu Bello University Zaria, Nigeria.

4. Department of Clinical Pharmacy and Pharmacy Management, Faculty of Pharmaceutical Sciences, Kaduna State University, Nigeria.

Correspondence author: uiibrahim.cph.@buk.edu.ng +2348038850147

\begin{abstract}
Hypertension is a chronic medical condition characterized by an elevated arterial blood pressure with increasing prevalence in developing countries including Nigeria. One of the integral elements in management of hypertension is adherence to medication and lifestyle modification. This study aimed to assess adherence level for anti-hypertensive medications among adult hypertensive patients attending public hospitals in Kano State, Nigeria. The study was a cross sectional prospective survey involving 600 patients from six public healthcare facilities selected by multistage sampling technique. Adherence status was assessed using Morisky medication adherence scale. Sociodemographic data and other factors that may influence adherence to hypertension medications were evaluated. Out of the 598 patients that participated in the study, only 178 (29.8\%) have their BP controlled based on JNC8. Three hundred and thirty two (55.5\%) out of 598 patients have good adherence, while 266 (45.5\%) have poor adherence. Of the 178 patients who had good BP control, 120 (67.5\%) have good adherence while 58 (32.5\%) have poor adherence. BP control was significantly higher in those that adhered to antihypertensive medication compared with non-adhering patients $\left(X^{2}=14.526\right.$; $d f=1$; $p$-value $=<0.001$ ). Additionally, Chi-square test showed significant association between number of antihypertensives and blood pressure control. ( $X 2=37.556 \mathrm{df}=3, p<0.001)$. The study established that $55.5 \%$ of the respondents have good adherence to their antihypertensive medication while $29.8 \%$ had their BP controlled. Adherence and number of antihypertensive medication a patient is taking were found to have significant relationship with $B P$ control.
\end{abstract}

Keywords: Medication, adherence, hypertension, antihypertensive

\section{INTRODUCTION}

Hypertension (HTN), high or sustain increased blood pressure (the systolic $\geq 140 \mathrm{mmHg}$ and diastolic level $\geq 90 \mathrm{mmHg}$ ), is a worldwide public health problem. It contributes to the burden of cardiovascular diseases, stroke, and renal failure leading to early mortality and disability (WHO, 2013). Global prevalence of adult hypertensive patients was about $22 \%$ in 2014 and was estimated to account for more than $40 \%$ of the African adult population (Juliet Addo, 2007). In Sub Saharan Africa, it varied from $6 \%$ to $48 \%$, that is 74.7 million hypertensive individuals and projected to be $68 \%$ (125.5 million) by 2025 (Shona Dalal, 2011, Ogah and Rayner, 2013). The combined prevalence rates of hypertension in Africa and Nigeria are $15 \%$ and $22 \%$, respectively (Ekwunife and Aguwa, 2011).

Hypertension is a modifiable cardiovascular risk factor for which there are available medications which are effective in regulating the raised blood pressure as well as preventing complications. However, the maximal beneficial effect of an appropriate treatment plan can be achieved only if patients strictly adhere to the medications and lifestyle changes. The primary focus of antihypertensive therapy is to achieve BP target of < 140 per $90 \mathrm{mmHg}$ for the general population and $<130$ per $80 \mathrm{mmHg}$ for special high-risk population such as patients with diabetes mellitus, renal disease and adverse 
Special Conference Edition, November, 2019 cardiovascular events such as myocardial infarction and stroke (Chobanian et al., 2003; WHO, 2003). There are various antihypertensive drugs that have been shown to effectively control blood pressure, thereby reducing the attendant risk of cardiovascular morbidity and mortality.

Blood pressure control is multifactorial (Chobanian et al., 2003; WHO, 2003; Familoni et al., 2003) and some of these factors relate to the patients, the health professionals and the government. One of the patient-related factors is adherence to antihypertensive medication. Adherence is one of the challenges of antihypertensive medication and is defined conceptually as the degree to which the patient conforms to treatment as prescribed (Laurelea and Roden, 2001) There is no 'gold standard' for precise measurement of adherence (Mallion \& Schmitt, 2001). However, several methods of measuring adherence to medication have been described (Mallion and Schmitt, 2001; Bitter, 1997; Averbach et al., 1997). Clinical measures include the use of questionnaires for 30 days of self-reported (self-administered) therapy. Pharmacological measures involve determination of serum and urinary concentrations of drugs or using biological markers integrated into the tablets. The pharmacological measures have a higher sensitivity and specificity, but are not routinely used in clinical practice (Bitter, 1997). Recently, the medication event monitoring system (MEMS) was introduced which is basically the assessment of adherence using the MEMS device which involves microprocessorbased monitoring (Averbach et al., 1997). However, the MEMS device is not readily available in most facilities.

Generally, good adherence to medications is an important achievement in disease management, and it is crucial to decrease complications like cardiovascular related morbidity and mortality (Donald et al., 2005; Brown and Bussell, 2011). However, to the best of our knowledge, particularly in the study areas, little is known about level of antihypertensive drug adherence among hypertensive patients. Therefore, this study aimed to assess adherence level for antihypertensive medications among adult hypertensive patients attending public hospitals in Kano State Nigeria.

\section{MATERIALS AND METHODS Study Population and Sample Size}

The study population consists of adult hypertensive patients attending hypertension clinics and receiving treatment in the hospitals.
These patients are followed up in the hospital for regular treatment and checkup depending on high blood pressure control. Based on WHO methodology (WHO, 1993), 6 health care facilities were included in the study and in each facility, 100 participants were randomly selected and assessed.

\section{Study Design}

The study was a cross sectional prospective survey involving six public health care facilities selected by multistage sampling technique. List and addresses of all registered health care facilities operating hypertension clinic in the State was obtained from the State Ministry of Health $(\mathrm{SMoH})$. Based on the list, the State was stratified into three using senatorial district as stratum. In north and south senatorial districts, one general hospital was selected, while in the central zone, 3 general hospitals were selected (because it has the highest population and more number of hospitals). In all the instances, selection was by simple random sampling using balloting system. Also the only available teaching hospitals was added to make-up the six facilities.

\section{Inclusion Criterion}

Hypertensive patients 18 years and above, patients on follow up appointments to the hospital, patients managed for hypertension for more than 6 months, patients consenting to participate in the study.

\section{Exclusion Criterion}

Sick patients on the appointment day requiring admission, pregnant hypertensive patients, individuals who were not capable of hearing and speaking, individuals with known mental disorders

\section{Data Collection Tool and Procedure}

Five pharmacy technicians were recruited as research assistants and trained on the objectives of the study as well as the data collection instruments.

Adherence status was assessed using the Morisky medication adherence scale -8 which is a self-reporting method to determine adherence. It contains eight questions with seven closed dichotomous (yes/no) answers and one Likert scale question. Each item measures specific adherence behavior. The degree of adherence was determined according to the score resulting from the sum of all the correct answers (Morisky et al., 1986). The questionnaire was translated to Hausa, the local language, for respondents who do not understand English. Also, sociodemographic data and other factors that may influence adherence to hypertensive medication were evaluated. 
Special Conference Edition, November, 2019

The questionnaire was pretested at Murtala Muhammad Specialist Hospital using 25 hypertensive respondents who were not included in the final sample of the study. Necessary adjustments to the questionnaires were made according to the findings of the pilot study to improve the reliability of the data to be collected in the study. The data collection technique was a face to face interview using the validated questionnaire. To avoid the chance of data recycling, a special mark was placed on each medical card of the respondents.

\section{Operational definitions}

Adherent: respondents who scored $\geq 6$ points of the Morisky medication adherence scale - 8 (Menditto et al., 2015).

Controlled Hypertension: maintaining the average BP reading less than $140 / 90 \mathrm{mmHg}$ at the time of data collection irrespective of measurements at other time.

\section{Data processing and analysis}

After each clinic day, data collected were entered into an excel spreadsheet where it was double checked by the principal investigator for errors and any other inconsistencies. After data collection, the entire database was exported to SPSS version 20 which was used for statistical analysis. Descriptive statistic including frequencies, means and standard deviations were calculated. Chi-square test was used to measure associations between variables.

\section{RESULTS}

In all the facilities, majority of the study participants were females except in Muhammadu Abdullahi Wase Specialist Hospital (MAWSH) where males constituted about $61 \%$ of the participants. The mean age of the participant from Murtala Muhammad Specialist Hospitals (MMSH) was the highest $(61.6 \pm 12.4)$ among the facilities while that of participants from Kura general hospital was the lowest $(44.4 \pm 15.5)$. Majority of the respondents in all the facilities were married, followed by widowed, divorced/separated and those who had never married.

Table 1: Respondents' Demographic Characteristics

\begin{tabular}{|c|c|c|c|c|c|c|c|}
\hline Variables & & KGH & DTGH & WGGH & MMSH & MAWSH & AKTH \\
\hline $\begin{array}{l}\text { variables } \\
\text { Mean Age ( } \pm S D)\end{array}$ & & $\begin{array}{c}44.4 \\
(15.5)\end{array}$ & $\begin{array}{c}52.9 \\
(15.3)\end{array}$ & $\begin{array}{c}58.7 \\
(14.4)\end{array}$ & $\begin{array}{c}61.6 \\
(12.4)\end{array}$ & $\begin{array}{c}54.8 \\
(11.7)\end{array}$ & $\begin{array}{c}49.0 \\
(13.2)\end{array}$ \\
\hline \multirow[t]{2}{*}{ Gender } & Male & 31 & 20 & 30 & 23 & 61 & 22 \\
\hline & Female & 66 & 77 & 70 & 76 & 38 & 78 \\
\hline \multirow[t]{4}{*}{ Marital Status } & Never Married & 0 & 0 & 5 & 1 & 3 & 5 \\
\hline & Married & 76 & 67 & 58 & 50 & 75 & 54 \\
\hline & Divorced/Separated & 1 & 0 & 5 & 7 & 9 & 7 \\
\hline & Widowed & 22 & 32 & 32 & 41 & 34 & 34 \\
\hline \multirow[t]{2}{*}{ Address } & Rural & 37 & 23 & 52 & 12 & 12 & 46 \\
\hline & Urban & 63 & 73 & 48 & 87 & 83 & 54 \\
\hline \multirow[t]{4}{*}{ Employment } & Formally Employed & 18 & 4 & 5 & 4 & 13 & 11 \\
\hline & Unemployed & 61 & 39 & 48 & 68 & 52 & 39 \\
\hline & Self Employed & 17 & 56 & 34 & 25 & 29 & 38 \\
\hline & Pensioner & 1 & 1 & 13 & 2 & 5 & 12 \\
\hline \multirow[t]{4}{*}{ Educational Level } & No Formal Education & 36 & 64 & 65 & 77 & 44 & 57 \\
\hline & Primary & 19 & 22 & 4 & 18 & 11 & 11 \\
\hline & Secondary & 24 & 6 & 19 & 3 & 24 & 16 \\
\hline & Post-Secondary & 18 & 3 & 12 & 1 & 20 & 16 \\
\hline
\end{tabular}

Key: KGH -Kura General Hospital, DTGH - Dawakin Tofa General Hospital, WGGH - Waziri Shehu Gidado General Hospital, MMSH - Murtala Muhammad Specialist Hospital, MAWSH - Muhammadu Abdullahi Wase Specialist Hospital, AKTH - Aminu Kano Teaching Hospital.

Those without formal education constituted the majority of the participants with 36, 64, 65, 77, 44, and 57 representing Kura General Hospital (KGH), Dawakin Tofa General Hospital (DTGH), Waziri Gidado General Hospital (WGGH), MMSH, MAWSH and Aminu Kano Teaching Hospital
(AKTH) respectively. In MAWSH, 20 participants reached post-secondary school, representing the highest among the facilities under study while MMSH had only 1 participant representing the lowest as shown in Table 1. 
Special Conference Edition, November, 2019

Table 2: Level of Blood Pressure control Among the Study Participants

\begin{tabular}{|c|c|c|c|c|}
\hline & & \multicolumn{2}{|c|}{ B.P CONTROL } & \multirow[b]{3}{*}{ Total } \\
\hline & & & Not Controlled & \\
\hline & & Controlled (\%) & $(\%)$ & \\
\hline \multirow[t]{6}{*}{ Location } & KGH & 36 & 62 & 98 \\
\hline & DTGH & $41(41)$ & $59(59)$ & 100 \\
\hline & WGGH & $22(22)$ & $78(78)$ & 100 \\
\hline & MMSH & $28(28)$ & $72(72)$ & 100 \\
\hline & MAWSH & $25(25)$ & $75(75)$ & 100 \\
\hline & AKTH & $26(26)$ & $74(74)$ & 100 \\
\hline Total & & $178(29.8)$ & $420(70.2)$ & 598 \\
\hline
\end{tabular}

$x 2=23.743 \mathrm{df}=5, \mathrm{p}<0.001$

Out of the 598 patients that participated in the study, only $178(29.8 \%)$ have their BP controlled.

DTGH has the highest number of patients with controlled B.P (41) while WGGH has the least (22) as shown in table 2.

Table 3-Association between Adherence and B.P Control

\begin{tabular}{|c|c|c|c|c|c|}
\hline \multirow[t]{2}{*}{ Adherence } & \multicolumn{2}{|c|}{ Controlled } & \multirow{2}{*}{$\begin{array}{c}\text { Not Controlled } \\
n\end{array}$} & \multirow[b]{2}{*}{$\%$} & \multirow[t]{2}{*}{ Total } \\
\hline & $n$ & $\%$ & & & \\
\hline $\begin{array}{l}\text { Poor } \\
\text { adherence }\end{array}$ & 58 & 32.5 & 208 & 49.5 & 266 \\
\hline $\begin{array}{l}\text { Good } \\
\text { adherence }\end{array}$ & 120 & 67.5 & 212 & 50.5 & 332 \\
\hline Total & 178 & & 420 & & 598 \\
\hline
\end{tabular}

$x^{2}=14.526 \mathrm{df}=1, \mathrm{p}<0.001$

Three hundred and thirty two (55.5\%) out of 598 patients have good adherence, while 266 $(45.5 \%)$ have poor adherence. Of the 178 patients who had good BP control, $120(67.5 \%)$ have good adherence while 58 (32.5\%) have poor adherence. BP control was significantly higher in those that adhered to antihypertensive medication compared with non-adhering patients $(X 2=14.526 ; \mathrm{df}=1 ; p$-value $=<0.001)($ Table $4)$. Blood pressure control by number of antihypertensive medications (Table 4). One hundred and seventy eight patients have their BP controlled of which 79 (44.4\%) where on two drugs combination. Patients on more than three drugs combination have the least BP control. Chi-square test showed significant association between number of antihypertensive and blood pressure control. $(X 2=37.556, d f=3, p<0.001)$ (Table 4).

TABLE 4: Blood Pressure Control by Number of Antihypertensive Medications

\begin{tabular}{lccccc}
\hline $\begin{array}{l}\text { Number of } \\
\text { Antihypertensive } \\
\text { Drugs }\end{array}$ & \multicolumn{2}{c}{ Controlled } & \multicolumn{2}{c}{ Not Controlled } & Total \\
& $\mathbf{n}$ & $\mathbf{\%}$ & $\mathbf{n}$ & $\mathbf{\%}$ & \\
\hline One Drug & 31 & 17.4 & 24 & 5.7 & 55 \\
Two Drugs & 79 & 44.4 & 134 & 31.9 & 213 \\
Three Drug & 58 & 32.6 & 230 & 54.8 & 288 \\
More than Three Drugs & 10 & 5.6 & 32 & 7.6 & 42 \\
Total & $\mathbf{1 7 8}$ & & $\mathbf{4 2 0}$ & & $\mathbf{5 9 8}$ \\
\hline
\end{tabular}

$x^{2}=37.556, \mathrm{df}=3, \mathrm{p}<0.001$

\section{DISCUSSION}

The study established that $55.5 \%$ of the respondents were fully adherent to their antihypertensive medication while $29.8 \%$ had their BP controlled. The BP control rate in this study is higher than that reported in Port Harcourt, Rivers State, south-south Nigeria in which $24.2 \%$ had controlled blood pressure of less than 140/90mmHg (Akpa et al. 2008).
However, other studies reported higher BP control of $31.4 \%$ and $33 \%$ by Ayodele et al., (2004) and Sani et al., (2008) respectively. The findings of this study agree with previous reports that adequate BP control rates are low in Nigeria and occur only in less than half of treated hypertensives (Ayodele et al., 2004; Akpa et al. 2008; Sani et al., 2008). 
Special Conference Edition, November, 2019

The high percentage of unrolled blood pressure is probably due to a number of factors such as poor patients' knowledge of hypertension and its treatment, inadequate healthcare facilities, misconceptions and health beliefs about hypertensive disorder (Oke and Bandele, 2004) Good adherence rate of $55.5 \%$ in this study is higher than that of $45.0 \%$ previously reported in some part of Kano, (Sani et al., 2008). The findings of this study have shown the importance of adherence in BP control amongst the study population. However, there may be other factors amongst the study population that may contribute to poor BP control despite adherence to medications.

Number of hypertension drugs the respondents were taking was associated with BP control $(p<0.001)$. Respondents who took two antihypertensive were more adherent than those who took other number of combinations. This is in contrast with the findings of a study carried out in Eastern part of the country (Iloh et al, 2013). Taking three or more drugs was associated with better BP control than any other number of combination in that study. Inkster et al. (2006) in a study to determine adherence to antihypertensive medication and association with patient and practice factors found no significant association between adherence and number of antihypertensives taken. However, those taking more than three antihypertensives would be more likely to develop adverse effects from the

\section{REFERENCES}

Akpa MR, Alasia DD, Emem-chioma PC. An appraisal of hospital based blood pressure control in Port Harcourt, Nigeria. Nigerian Health J. 2008;8:2730.

Averbach $M$, Weintraaban $M$, Pollack DJ. Compliance assessment in clinical trials: The MEMS device. J Clin Resp Pharmaco-epidemiol. 1997;4:199-204.

Ayodele OE, Alebiosu CO, Salako BL. Differential control of systolic and diastolic blood pressure in blacks with essential hypertension. J Natl Med Assoc. 2004;96:310-314. PMid: 15040512, PMCid:2594866

Bitter N. Maintaining long term control of blood pressure: The role of improved compliance. Clin Cardiol. 1997;18:1226. clc. 4960181504

http://dx.doi.org/10.1002/

Brown MT, Bussell JK. Medication adherence: WHO cares? Mayo Found Med Educ Res. 2011;86(4):304-14.

Chobanian AV, Bakris GL, Black HR, et al. The seventh report of the Joint National drugs, which would affect compliance to treatment as some patients opt to discontinue the drugs or skip them for a while. Higher numbers of antihypertensives also mean higher cost for the drugs thus resulting some patients inability to purchase the prescribed drugs and consequently poor adherence.

\section{CONCLUSION}

The study established that $55.5 \%$ of the respondents have good adherence to their antihypertensive medication while $29.8 \%$ had their BP controlled. Adherence and number of antihypertensive medication a patient is taking were found to have significant relationship with BP control.

\section{RECOMMENDATION}

Healthcare providers should put more efforts to ensure that their adult hypertensive patients adhere to their antihypertensive medications. This could be through organizing regular lectures on the importance of adherence and educating the patients on hypertension and its treatments. Additionally, getting feedback from the patient about adherence and other factors that can affect the adherence is necessary to achieve target BP. Without regular feedback on medication adherence between healthcare providers and hypertensive patients, a patient with poor BP control may not achieve BP target.

Committee on Prevention, Detection, Evaluation and Treatment of high blood pressure: The JNC VII report. JAMA. 2003; 289:2560-2572. http://dx.doi.org/10.1001/jama.289.19.2 560, PMid: 12748199

Donald E, Morisky S, Alfonso A, et al. Predictive validity of a medication adherence measure in an outpatient setting. Am J Med Sci. 2005;330 (3):128-33.

Ekwunife OI and Aguwa CN. A meta-analysis of prevalence rate of hypertension in Nigerian populations. J. Public Health Epidemiol. 2011, 3(13): 604-607.

Familoni OB, Alebiosu CO, Odusan A, Raimi A. Factors influencing target organ damage among hypertensive patients. Tropical Cardiol. 2003; 29:21-24.

Iloh GUP, Ofoedu JN, Njoku PU, Amadi AN, Godswill-Uko EU. Medication adherence and blood pressure control amongst adults with primary hypertension attending a tertiary hospital primary care clinic in Eastern Nigeria. Afr J Prm Health Care Fam Med. 2013;5(1), Art. \#446, 6 pages. 
Special Conference Edition, November, 2019

http://dx.doi.org/10.4102/

phcfm.v5i1.446

Inkster ME, Donnan PT, MacDonald TM, Sullivan FM, Fahey $T$ (2006) Adherence to antihypertensive medication and association with patient and practice factors. J HumHypertens 20: 295-297

Juliet Addo LS, Leon DA. Hypertension in SubSaharan Africa a systematic review. Am Heart Assoc. 2007; 50:1012-8.

Laurelea $E$, Roden DM. Principles of prescription order writing and patient compliance. In Gilman G, Hardman JG, Limbard LE, editors. The Pharmacological Basis of Therapeutics. 10th edn. New York: McGraw Hill, 2001; p. 1911-1914.

Mallion JM, Schmitt D. Patient compliance in the treatment of arterial hypertension. Eur Soc Hypertens Sci News. 2001;2:7.

Menditto E, Guerriero F, Orlando V, Crola C, Di Somma C, Illario M, Morisky DE, Colao A. Self-Assessment of Adherence to Medication: A Case Study in Campania Region Community-Dwelling Population. J Aging Res. 2015; 682503.

Morisky DE and Levine G. Concurrent and predictive validity of a self-reported measure of medication adherence. Med Care. 1986; 24:67-74.

Ogah OS, Rayner BL. Recent advances in hypertension in sub-Saharan Africa. Heart: BMJ. 2013; 99(19):1390-7.

Oke DA, Bandele EO. Misconceptions of hypertension. J. Natl. Med. Assoc.
2004;96:1221-1224. PMid:15481752, PMCid:2568468

Sani MU, Mijinyawa MS, Adamu B, Abdu A, Borodo MM. Blood pressure control among treated hypertensives in a tertiary health institution. Niger ] Med. 2008;17:270-274.

http://dx.doi.org/10.4314/njm.v17i3.373 94, PMid: 18788251

Shona Dalal JJB, Jimmy V, Clement A, Francis B, Marina Njelekela DM, Wafaie $F$, Walter W, Hans-Olov A, Holmes MD. Noncommunicable diseases in sub- Saharan Africa: what we know now. Int J Epidemiol. 2011;40:885-901.

World Health Organization and International Network for Rational Use of Drugs (1993). How to investigate drug use in health facilities: Selected drug use indicators. EDM Research Series No. 7 [WHO/DAP/93.1]. Geneva: World Health Organization, IOS Press

WHO. World health day A global brief on hypertention. Switzerland: WHO Press; 2013.

World Health Organization-International Society of Hypertension. 2003 WHO-ISH Statement on Management of Hypertension. J Hypertens. 2003; 21:1983-1992. http://dx.doi.org/10.1097/00004872200311000-00002, PMid: 14597836 